INTERNATIONAL JOURNAL OF MULTIdisciplinARY RESEARCh AND ANALysis

ISSN(print): 2643-9840, ISSN(online): 2643-9875

Volume 04 Issue 11 November 2021

DOI: 10.47191/ijmra/v4-i11-45, Impact Factor: 6.072

Page No.- 1769-1771

\title{
Development Of Feeding Norms for Medium-Fiber and Fine-Fiber Cotton Varieties
}

\author{
Mukhiddin Movlonov ${ }^{1}$, Renat Nazarov ${ }^{2}$, Jurakhon Abdullaev ${ }^{3}$ \\ ${ }^{1}$ PhD Student, Research Institute of Cotton Breeding, Seed Production and Cultivation Agro-technology \\ ${ }^{2}$ Doctor of Agricultural Sciences, Professor, Research Institute of Cotton Breeding, Seed Production and Cultivation Agro- \\ technology \\ ${ }^{3}$ Chief Specialist of the Agricultural Research and Production Center
}

\begin{abstract}
In the Strategy of Agricultural Development of the Republic of Uzbekistan for 2020-2030, the President of the Republic of Uzbekistan identified the development of the production system of research, educational and consulting services in agriculture as a priority and developed a roadmap for its implementation.
\end{abstract}

KEYWORDS: Accumulation, cotton, Physiological experiments, Kashkadarya region, phosphorus, potassium, Irrigation, phenological observations.

\section{INTRODUCTION}

The development of cotton depends on many factors. Great care should be taken to accelerate the development of seedlings. Deficiency of essential nutrients disrupts the normal course of life processes in the body of cotton, resulting in reduced yields. Physiological experiments show that cotton consumes different amounts of nutrients at different times during the growing season.

Once the organic matter begins to accumulate in the cotton, they begin to absorb nutrients. Accumulation of organic matter in cotton absorbs a total of $0.16 \%$ of the total amount of nitrogen, phosphorus, potassium from germination to the formation of 2-3 petals, $4.68 \%$ from the emergence of 2-3 petals before flowering, from pruning to the flowering period - 23.8, it is clear that from the time of flowering to the beginning of ripening -65.04 percent, from the time of flowering to the end of the season -6.12 percent.

\section{THE MAIN FINDINGS AND RESULTS}

Each fertilizer is absorbed to varying degrees in the soil. Experiments confirm that the level of nitrogen in cotton is about 40-50 percent, phosphorus - 15-20, potassium - 50-60 percent.

According to the data, cotton is such a crop that it changes from time to time depending on the stages of growth and development. Scientists have developed a method of using fertilizers at different stages of plant growth and development, taking into account the demand for cotton and soil-climatic conditions. $(4,5,10)$

One way to increase the effectiveness of fertilizers is determined by the nutrient requirements of cotton varieties depending on their biological properties.

In recent years, the deterioration of soil salinity reclamation requires the creation of new varieties suitable for certain soil conditions and the development of their agro-techniques, along with research on agricultural techniques of agricultural crops.

Therefore, the improvement of soil reclamation in the conditions of different salinity soils of Kashkadarya region, along with improving the efficiency of soil, water, mineral and organic fertilizers, improving the yield and quality of crops, is a topical issue today.

Field experiments were conducted at the research and experimental station of the Research Institute of Cotton Breeding, Seed Production and Agro-technology in Karshi district of Kashkadarya region in the conditions of moderately saline bald soils. The studies examined the effects of soil fertility on moderately saline soils of cotton, fertilizer standards on feeding norms of medium-fiber and fine-fiber cotton varieties on its growth and development.

Experiments, phenological observations, sampling of plants were carried out in accordance with the manual "Irrigation experiment technique", "Methods of field experiments" (Tashkent, 2007).

The average annual air temperature is always $+150 \mathrm{C}$. The warmest days of the year are $240-245$ days. 


\section{Development Of Feeding Norms for Medium-Fiber and Fine-Fiber Cotton Varieties}

The sum of useful temperatures for plants is 2330-29910S. In the Karshi desert it is very convenient to grow fine-fiber cotton and heat-loving crops (L.N.Babushkin, 1964, F.A.Muminov, 1991).

The purpose of this experiment is to develop scientifically based recommendations for farms to obtain high yields of cotton, based on the importance of fertilizer standards in the agro-technology of cultivation of newly created medium-fiber Bukhara-10 and fine-fiber cotton Surkhan-14 in medium saline soils of Kashkadarya region.

The Bukhara-10 medium-fiber variety was created at the Bukhara Research and Experimental Station of the Research Institute of Cotton Breeding, Seed Production and Agrotechnology. It belongs to the genus Gossipium-xirzitum and is one of the fastest growing varieties. "Bukhara-10" was obtained by artificial hybridization by cross-breeding of varieties "Bukhara-6", "An-Bayavui2 " and repeated individual selection (8).

According to biological characteristics, Bukhara-10 variety ripens 7-10 days before Bukhara-6 variety, depending on weather conditions and care. The cocoons are five-lobed, with a snout, the lobe opens wide and does not spill. Adapted for cotton picking machine. Growth period -108-115 days, yield -45-50 ts / ha, weight in one pod 8-9 grams, weight of 1000 seeds $135-150$ grams, fiber yield 36.5-38.5\%, fiber softness -6200-6500, fiber hardness -4.5-4.6 hectares, yield -20.7-23.0 percent, micronaire - 4.1-4.4, fiber type in average agro-technics-IV.

Surkhan-14 cotton variety was created at the Research Institute of Cotton Breeding, Seed Production and Cultivation Agrotechnologies from hybrid combinations of Ashgabat-53 and Karshi-6 varieties.

Surkhan-14 variety is bred in the elite farm "Surkhan" in Jarkurgan district.

The stem of Surkhan-14 variety is unbranched (limited branching), the fruiting branches are gypsum on the main stem. The first crop grows on the horn-3-4 joints, which indicates a very high degree of maturity (12-118 days). The flower is large, markedly antacid spots.

The pelvis has 3-4 pelvis, in some cases 5 pelvis.

A characteristic feature is that the fiber is firmly located in the stalk, and the crop does not fall out of the stalk, and this feature can be called a "wind-resistant" variety. This trait is a genetic marker trait that can be used to determine the similarity of a variety in a breeding experiment. Microneyri -4.0-4.1.

The size of the pod is 3.2-3.4 grams, fiber consumption is $35-37 \%$, the yield of the variety is $40-45$ ts / ha in the state variety test, $35-40$ ts / ha in production. According to the state standard, the fiber of Surkhan-14 variety meets the requirements of type 1 "B".

All experiments were carried out in 3 turns and in different variants, between rows $90 \mathrm{~cm}$ wide, consisting of 8 rows, 50 $\mathrm{m}$ long and $7.2 \mathrm{~m}$ wide. The total area of each variant was $360 \mathrm{~m}^{2}$, of which the total area of the 12 variants was 0.432 ha, with $1.3 \mathrm{ha}$ in the three rotations.

\section{CONCLUSION}

The experimental field is moderately saline bare soil, medium sandy in mechanical composition, groundwater level is around $1.5-2.0$ and $2.5-3.0 \mathrm{~m}$.

Plants N-180, leaving a seedling thickness of 80-90 thousand / ha per hectare; R-126; When fed at the rate of K-90 kg / ha, the medium-fiber Bukhara- 6 cotton variety weighed $6.1 \mathrm{~g}$ of cotton per bush, leaving the seedlings $\mathrm{N}-210$ at a seedling thickness of 80-90 thousand / ha per hectare; R-147; The weight of medium-fiber Bukhara-10 cotton variety fed in K-05 kg / game weighed 7.0 grams. Plants N-280, leaving 120-130 thousand / ha of seedlings per hectare; R-196; The weight of cotton in one stalk of fine-grained cotton varieties Surkhan-14 fed at the rate of K-140 kg / ha was 3.6 grams.

In the experimental field, 32.6-46.5 $\mathrm{t} / \mathrm{ha}$ of medium-fiber cotton varieties and 36.2-41.5 $\mathrm{t} / \mathrm{ha}$ of fine-fiber cotton varieties were harvested.

To obtain a high yield from a medium-fiber cotton variety, leave it at a seedling thickness of 100-120 thousand / ha per hectare, N-210; P-147; N-280, leaving 120-130 thousand seedlings per hectare for R-105 kg / ha and high yields of fine-fiber cotton; $\mathrm{R}-196$; Feeding at a rate of $\mathrm{K}-140 \mathrm{~kg} / \mathrm{ha}$ is advisable.

\section{REFERENCES}

1) Decree of the President of the Republic of Uzbekistan PD-5853 "On approval of the Strategy of agricultural development of the Republic of Uzbekistan for 2020-2030".

2) Babushkin L.N. (1964) Agroclimatic descriptions of Central Asia - Proceedings of the Tashkent State University. v.286. pp. 5-185.

3) Muminov F.A. (1991) Weather, climate and cotton, Leningrad, hydrometeoizdat. - pp. 3-199.

4) Axmadjanov B. (2006) Yield quality depends on what. Journal of Agriculture of Uzbekistan. № 4. - p. 16.

5) Toshqo'ziev M. (2009) "Improving the fertility and reclamation of irrigated lands". Current issues in cotton growing and prospects for its development. - pp. 129-139. 


\section{Development Of Feeding Norms for Medium-Fiber and Fine-Fiber Cotton Varieties}

6) Dospekhov B.A. (1985) Field experiment technique. M-Agropromizdat. - pp. 248-255.

7) Methods of agrochemical analyzes of soils and plants in Central Asia. - Tashkent. 1977 ed. 5.

8) Djumaev Sh.B., Raxmatov I.M., Choriev R.M. (2006) Results of ecological testing of cotton varieties in desert conditions. Scientific bases of development of cotton growing and grain growing. - Tashkent. - pp. 446-448.

9) Nazarov R.S. (1996) Genotypic specificity of cotton mineral nutrition. Reports of the Academy of Sciences of the Republic of Uzbekistan. - Tashkent. No. 6. - pp. 50-56.

10) Belousov M.A. (1975) physiological foundations of cotton nutrition. - Tashkent. Fan. 